E-ISSN : 2549-6581

DOI: 10.21776/ub.JOIM.2019.003.03.2

Artikel Hasil Penelitian

Diterima : 2 Juli 2018

Direview : 16 Oktober 2019

Dimuat : Desember 2019 - Maret 2020
OPEN ACCESS

Journal of Issues in Midwifer

\title{
Pengaruh Riwayat Pemakaian Popok dan Metode Toilet Training terhadap Keberhasilan Toilet Training pada Anak Balita Usia 18-48 Bulan di Malang
}

\author{
Cindy Irmayanti ${ }^{\left.1^{*}\right)}$, Endang Sri Wahyuni ${ }^{2}$, Mustika Dewi ${ }^{3}$ \\ ${ }^{\left.1^{*}\right)}$ Program Studi S1 Kebidanan, Email: cindyirmayanti1@gmail.com: Fakultas Kedokteran, \\ Universitas Brawijaya, Telp: +6289613153631 \\ ${ }^{2}$ Laboratorium IImu Faal, Fakultas Kedokteran, Universitas Brawijaya, \\ Email: endang sw46@yahoo.com \\ ${ }^{3}$ Program Studi S1 Kebidanan, Fakultas Kedokteran, Universitas Brawijaya, \\ Email: mustikadewi.eka@gmail.com
}

\begin{abstract}
Toilet training is the challenging stages of development that all children are required to successfully complete it to achieve independence and self-esteem. In the last few decades, there has been a trend of late success on toilet training accompanied by a change in diapering habit, which today tends to be more disposable diaper than cloth diaper. In addition, toilet training method (parent oriented, child oriented and combination of the two) is a training provided by parents also have an important aspect in the success of toilet training. The research aim to know the effect of history of the diaper usage and toilet training method to the success of toilet training in children aged 18-48 months in five Maternal and Child Health Center (Posyandu) Malang 2017. The research used analytic observational with case-control approach by using chi square and logistic regression test. The number of selected samples is 70 based on cluster random sampling technique. The result is a history of diaper usage on the success of toilet training $(p=0,003)$, as well as toilet training method $(p=0,003)$. In logistic regression, the results of cloth diaper users have a tendency to reach toilet training success of 4.6 times than disposable diaper users and who use parent oriented methods tend to achieve successful toilet training of 5.6 times than those using child oriented methods. The research conclude that there is a significant effect of the history of diaper usage and toilet training method on the success of toilet training.
\end{abstract}

Key words: toilet training, disposable diaper, cloth diaper, toilet training method

\begin{abstract}
ABSTRAK
Toilet training adalah salah satu tahap perkembangan yang menantang pada awal kehidupan anak, yang semua anak diharuskan dapat berhasil menyelesaikannya untuk mencapai kemandirian dan penghargaan diri. Beberapa dekade terakhir, terjadi tren keterlambatan keberhasilan toilet training yang disertai dengan perubahan kebiasaan pemakaian popok yang saat ini cenderung lebih banyak pemakaian popok sekali pakai daripada popok kain. Oleh karena itu, pemakaian popok diduga menjadi salah satu faktor yang berpengaruh terhadap keberhasilan toilet training. Selain itu, metode toilet training merupakan pelatihan yang diberikan oleh orang tua juga berperan penting
\end{abstract}


dalam keberhasilan toilet training. Metode toilet training yang paling sering digunakan saat ini yaitu parent oriented, child oriented dan kombinasi antara keduanya. Tujuan penelitian adalah untuk mengetahui pengaruh riwayat pemakaian popok dan metode toilet training terhadap keberhasilan toilet training pada anak balita usia 18-48 bulan di lima Posyandu Kota Malang Tahun 2017. Desain penelitian ini adalah observasional analitik dengan pendekatan case-control dengan menggunakan uji chi square dan regresi logistik. Jumlah sampel terpilih adalah 70 berdasarkan teknik cluster random sampling. Hasilnya adalah riwayat pemakaian popok berpengaruh terhadap keberhasilan toilet training $(p=0,003)$, begitu pula dengan metode toilet training $(p=$ 0,003). Pada regresi logistik, didapatkan hasil pemakai popok kain memiliki kecenderungan mencapai keberhasilan toilet training sebesar 4,6 kali daripada pemakai popok sekali pakai dan yang menggunakan metode parent oriented cenderung mencapai keberhasilan toilet training sebesar 5,6 kali daripada yang menggunakan metode child oriented. Kesimpulan penelitian ini adalah terdapat pengaruh yang bermakna dari riwayat pemakaian popok dan metode toilet training terhadap keberhasilan toilet training.

Kata Kunci: toilet training, popok sekali pakai, popok kain, metode toilet training

*Korespondensi: Cindy Irmayanti. Surel: cindyirmayanti1@gmail.com

\section{PENDAHULUAN}

Toilet training adalah salah satu tahap perkembangan yang menantang pada kehidupan awal anak dan salah satu tugas yang semua anak diharuskan dapat berhasil menyelesaikannya untuk memenuhi tuntutan masyarakat berdasarkan nilai dan norma yang berlaku, serta untuk mencapai kemandirian dan penghargaan diri [1]. Toilet training dapat dimulai pada usia anak 18-24 bulan. Pelaksanaan toilet training harus disesuaikan dengan kematangan perkembangan anak karena toilet training membutuhkan persiapan dari berbagai aspek mulai dari fisik aitu motorik, kognitif dan mental [2].

Keberhasilan toilet training dipengaruhi oleh beberapa faktor, salah satunya adalah metode yang digunakan oleh pengasuh untuk melakukan toilet training. Metode yang dideskripsikan beberapa dekade terakhir ini ada dua yaitu child-oriented approach dan parentoriented approach. Child-oriented approach adalah pendekatan toilet training yang dimulai dengan menunggu kesiapan anak dan dilakukan tanpa memaksa serta tidak adanya peraturan yang mutlak sedangkan approach adalah metode pembelajaran toilet training yang intensif dan terstruktur yang ditandai dengan adanya jadwal yang teratur. Sampai saat ini belum terdapat data yang menjelaskan metode yang paling efektif dalam mencapai keberhasilan toilet training ${ }^{[3]}$.

Menurut sebuah jurnal penelitian, disebutkan bahwa beberapa dekade terakhir terjadi keterlambatan keberhasilan toilet training di negara-negara berkembang [2]. Tren keterlambatan keberhasilan toilet training tersebut disertai dengan perubahan kebiasaan pemakaian popok (diapering habits) yang saat ini cenderung lebih banyak pemakaian popok sekali pakai (disposable diapers) dengan daya serap yang tinggi (disposable absorbent diapers) daripada popok kain (cloth diaper) [1].

Penggunaan popok sekali
pakai disposable berhubungan dengan keterlambatan 
pengenalan dan respon terhadap sensasi penuh kandung kemih [4]. Anak tidak menyadari bahwa telah buang air pada popoknya karena daya serap yang tinggi pada popok sekali pakai (disposable diaper) sehingga popoknya tetap kering. Hal tersebut menyebabkan anak sulit mengontrol buang air kecil secara sadar yang akan berdampak pada keberhasilan toilet training ${ }^{[5]}$.

Penggunaan popok kain (cloth diaper) semakin jarang ditemukan pada beberapa dekade terakhir ini. Dalam hasil studi pendahuluan di Posyandu RW 2 Kelurahan Lawang didapatkan data hanya $20 \%$ ibu yang memakaikan popok kain (cloth diaper) tali kepada anaknya dan hanya sampai usia $\leq 5$ bulan kemudian dilanjutkan pemakaian popok sekali pakai (disposable diaper) serta $30 \%$ anak belum berhasil toilet training pada usia 3843 bulan. Hal tersebut menunjukkan bahwa pemakaian popok kain (cloth diaper) semakin tergeser oleh popok sekali pakai (disposable diaper) dan terjadi keterlambatan keberhasilan toilet training.

Popok kain (cloth diaper) harus lebih sering diganti karena daya serap yang tidak sebaik popok sekali pakai (disposable diaper). Hal tersebut menyebabkan anak dapat lebih peka dan mengembangkan rasa tidak nyaman akibat popok yang basah sehingga lebih mudah diajarkan toilet training [6]. Studi pendahuluan anak usia 2-4 tahun di Kota Malang menunjukkan bahwa $10 \%$ balita merupakan pemakai popok kain (cloth diaper) dan telah berhasil dalam toilet training dan sisanya (90\%) merupakan pemakai popok sekali pakai (disposable diaper). Sebanyak $67 \%$ dari pemakai popok sekali pakai (disposable diaper) belum berhasil dalam toilet training pada usia 3-3,5 tahun.

Keterlambatan keberhasilan toilet training pada anak menyebabkan keterlambatan kontrol buang air. Beberapa dampak akibat keterlambatan kontrol buang air adalah meningkatkan prevalensi gangguan fungsi eliminasi, infeksi saluran kemih, enuresis (mengompol), konstipasi, menolak toileting, encorepsis (gangguan kontrol buang air besar) dan gangguan kepercayaan diri [2].

Tujuan dari penelitan ini adalah untuk mengetahui pengaruh riwayat pemakaian popok dan metode toilet training terhadap keberhasilan toilet training pada anak balita usia 18 bulan sampai 4 tahun di Kota Malang tahun 2017.

\section{METODE PENELITIAN}

\section{Rancangan/Desain Penelitian}

Desain penelitian ini adalah penelitian observasional analitik yang menggunakan pendekatan case-control. Pembagian kelompok didasarkan atas ada atau tidaknya efek/disease, dalam penelitian ini kelompok kasus adalah kelompok yang belum mencapai keberhasilan toilet training sedangkan kelompok kontrol adalah kelompok yang telah mencapai keberhasilan toilet training.

\section{Sumber Data}

Sumber data primer yaitu karakteristik responden, riwayat pemakaian popok, penggunaan metode toilet training dan keberhasilan toilet training ditanyakan langsung oleh peneliti 
(wawancara) berdasarkan kuisioner yang telah disediakan. Data sekunder meliputi gangguan perkembangan, disabilitas intelektual dan catatan kesehatan selama kelahiran dan posyandu didapatkan dari Buku KIA (Kesehatan Ibu dan Anak).

\section{Sasaran Penelitian (Populasi/Sampel/Subjek Penelitian)}

Populasi penelitian adalah lbu atau bapak atau pengasuh beserta dengan anak balita nya yang berusia 18-48 bulan yang berdomisili di kelurahan-kelurahan tempat tinggal pemakai popok kain (cloth diaper) di Kota Malang tahun 2017.

Dalam penelitian ini, skala variabel independen dan dependen adalah nominal sehingga menggunakan rumus sampel untuk penelitian analitis kategorik yang disebutkan oleh Dahlan [7] yang menghasilkan jumlah sampel minimal adalah 62 .

Dikarenakan perbandingan pengguna popok kain (cloth diaper) dan popok sekali pakai (disposable diaper) yang disebutkan dalam berita adalah 1:9 dan juga demikian berdasarkan studi pendahuluan maka pengguna popok kain (cloth diaper) tidak dapat ditemukan dengan mudah. Oleh karena itu, peneliti hanya akan menggunakan tempat tinggal pengguna popok kain (cloth diaper) sebagai acuan untuk mempermudah menemukan sampel sesuai kriteria.

Pengambilan sampel dimulai dengan mendata ibu-ibu yang memakaikan popok kain (cloth diaper) pada anaknya yang tinggal di Kota Malang. Peneliti mencari data melalui Komunitas Popok Kain di akun media sosial. Dengan teknik total sampling, terdapat 10 ibu terpilih yang sesuai kriteria dan bersedia berpartisipasi dalam penelitian.

Selanjutnya peneliti mendata alamat dari 10 ibu tersebut untuk mengetahui variasi tempat tinggalnya (kelurahan). Selanjutnya dilakukan teknik cluster random sampling. Berdasarkan pendataan alamat, ditemukan terdapat 7 macam kelurahan tempat tinggal ibu-ibu tersebut.

Kemudian dipilih 5 kelurahan secara acak. Dari 5 kelurahan tersebut, peneliti memilih satu RW dari masing-masing kelurahan. Dengan demikian, peneliti melakukan pengambilan data di 5 posyandu yang berbeda.

Sampel yang dimaksud harus memiliki kriteria sebagai berikut :

Kriteria inklusi

a. Ibu yang mengasuh balita yang berusia 18 bulan sampai 4 tahun selama $75 \%$ dari usia anak atau ibu tersebut yang melakukan pelatihan toileting dan mengetahui riwayat pemakaian popok anaknya.

b. Bersedia menjadi responden penelitian dan menandatangani lembar inform consent.

c. Ibu dan anak dalam kondisi sehat saat penelitian.

d. Ibu dapat membaca dan menulis.

e. Ibu masih memiliki buku KIA atau catatan riwayat kesehatan anaknya.

Kriteria eksklusi

a. Ibu yang memiliki balita dengan gangguan perkembangan. 
b. Ibu yang memiliki balita dengan disabilitas intelektual.

c. Ibu yang memiliki balita dengan kelainan sistem perkemihan dan pencernaan.

\section{Pengembangan Instrumen dan Teknik Pengumpulan Data}

Berikut adalah instrumen yang digunakan peneliti untuk mengumpulkan data:

a. Buku KIA untuk mengetahui riwayat kesehatan balita.

b. Kuisioner untuk mengetahui karakteristik sampel, riwayat pemakaian popok, metode toilet training dan keberhasilan toilet training.

\section{Teknik Analisis Data}

Data penelitan akan dianalisis menggunakan SPSS for Windows 16.0. Analisis univariat

\section{HASIL PENELITIAN}

\section{Uji Univariat}

Tabel 1. Distribusi Frekuensi Karakteristik Responden

\begin{tabular}{|c|c|c|c|}
\hline No & Karakteristik & $\mathrm{N}$ & $\%$ \\
\hline 1. & Usia Anak (bulan) & & \\
& a. $18-24$ & 12 & 15 \\
& b. $>24-30$ & 15 & 22 \\
& c. $>30-36$ & 14 & 21 \\
& d. $>36-42$ & 9 & 13 \\
& e. $>42-48$ & 20 & 29 \\
\hline 2. & Usia Mulai Pelatihan & & \\
& BAB (bulan) & 11 & 8,5 \\
& a. $<18$ & 15 & 21,4 \\
& b. $18-<24$ & 34 & 48,5 \\
& c. 24-30 & 6 & 8,5 \\
& d. >30-36 & 4 & 6 \\
& e. Belum saat & & \\
\hline \multirow{1}{*}{3.} & Usia Mulai Pelatihan & & \\
& BAK (bulan) & 10 & 14,3 \\
& a. <18 & 20 & 28,6 \\
& b. 18-<24 & 35 & 50 \\
& c. 24-30 & 4 & 5,7 \\
\hline
\end{tabular}

digunakan untuk menganalisis karakteristik responden secara deskriptif. Analisis bivariat untuk mengetahui pengaruh riwayat pemakaian popok dan pengaruh metode toilet training terhadap keberhasilan toilet training serta menggunakan Chi Square Test dengan tingkat kemaknaan 95\% dan dikatakan bermakna jika nilai $p<0,05$. Setelah diketahui hasil analisis bivariat, dilakukan analisis multivariat dengan menggunakan logistic regression test untuk mengetahui pengaruh kedua variabel bebas tersebut secara bersama-sama terhadap keberhasilan toilet training. Selain itu, juga dapat diketahui nilai odds ratio.

\begin{tabular}{|c|c|c|c|}
\hline & $\begin{array}{ll}\text { d. } & >30-36 \\
\text { e. } & \text { Belum saat } \\
& \text { penelitian }\end{array}$ & 1 & 1,4 \\
\hline 4. & $\begin{array}{l}\text { Keberhasilan Toilet } \\
\text { Training } \\
\begin{aligned} \text { a. } & \text { Belum } \\
& \text { behasil } \\
\text { b. } & \text { Berhasil }\end{aligned}\end{array}$ & $\begin{array}{l}40 \\
30\end{array}$ & $\begin{array}{l}57,1 \\
42,9\end{array}$ \\
\hline 5. & 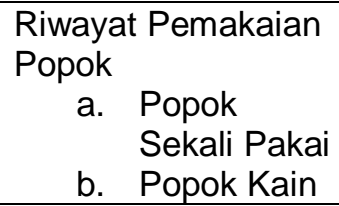 & $\begin{array}{l}56 \\
14\end{array}$ & $\begin{array}{l}80 \\
20\end{array}$ \\
\hline 6. & $\begin{array}{l}\text { Metode Toilet } \\
\text { Training } \\
\text { a. Child } \\
\text { oriented } \\
\text { b. Parent } \\
\text { oriented } \\
\text { c. Mix }\end{array}$ & $\begin{array}{l}24 \\
25 \\
21\end{array}$ & $\begin{array}{c}34,3 \\
35,7 \\
30\end{array}$ \\
\hline
\end{tabular}


Pada tabel 1 dapat diketahui bahwa jumlah anak yang belum berhasil toilet training lebih banyak daripada yang telah berhasil yaitu sebesar $57,1 \%$ dan anak balita yang memiliki riwayat pemakaian popok sekali pakai jauh lebih banyak daripada yang memakai popok kain yaitu sebesar $80 \%$. Metode toilet training yang paling sering diterapkan orang tua atau pengasuh adalah metode parent oriented yaitu sebesar $35,7 \%$.

\section{Uji Bivariat}

Tabel 2. Tabel Silang Pengaruh Riwayat Pemakaian Popok terhadap Keberhasilan Toilet Training

\begin{tabular}{|c|c|c|c|c|c|}
\hline & \multicolumn{2}{|c|}{ Keberhasilan Toilet training } & \multirow[b]{2}{*}{ Total } & \multirow[b]{2}{*}{$p$} \\
\hline & & Belum Berhasil & Berhasil & & \\
\hline \multirow{2}{*}{$\begin{array}{l}\text { Riwayat } \\
\text { Pemakaian } \\
\text { Popok }\end{array}$} & $\begin{array}{c}\text { Popok Sekali } \\
\text { Pakai }\end{array}$ & $\begin{array}{c}37 \\
66,1 \%\end{array}$ & $\begin{array}{c}19 \\
33,9 \%\end{array}$ & $\begin{array}{c}56 \\
100 \%\end{array}$ & \multirow[t]{3}{*}{0,003} \\
\hline & Popok Kain & $\begin{array}{c}3 \\
21,4 \%\end{array}$ & $\begin{array}{c}11 \\
78,6 \%\end{array}$ & $\begin{array}{c}14 \\
100 \%\end{array}$ & \\
\hline \multicolumn{2}{|l|}{ Total } & $\begin{array}{c}40 \\
57,1 \%\end{array}$ & $\begin{array}{c}30 \\
42,9 \%\end{array}$ & $\begin{array}{c}70 \\
100 \%\end{array}$ & \\
\hline
\end{tabular}

Sumber : Data Penelitian Primer, 2017

Pada tabel 2 menunjukkan bahwa capaian keberhasilan toilet training lebih besar pada kelompok anak balita yang menggunakan popok kain yaitu sebesar 78,6\% daripada anak balita yang menggunakan popok sekali pakai yang hanya sebesar 33,9\%. Namun sebaliknya, persentase anak balita yang belum berhasil toilet training lebih besar pada kelompok popok sekali pakai yaitu sebesar 66,1\% dibandingkan dengan kelompok popok kain yang hanya sebesar $21,4 \%$. Hasil tersebut dianalisis menggunakan chi square test dan menunjukkan nilai signifikansi $p=0,003 \quad(<0,05)$ sehingga dapat diinterpretasikan bahwa dalam penelitian ini terdapat pengaruh yang bermakna dari riwayat pemakaian popok terhadap keberhasilan toilet training pada anak balita usia 18-48 bulan Kota Malang. 
Tabel 3. Tabel Silang Pengaruh Metode Toilet Training terhadap Keberhasilan Toilet Training

\begin{tabular}{|c|c|c|c|c|c|}
\hline & \multicolumn{2}{|c|}{ Keberhasilan Toilet training } & \multirow[b]{2}{*}{ Total } & \multirow[b]{2}{*}{$p$} \\
\hline & & Belum Berhasil & & & \\
\hline \multirow{3}{*}{$\begin{array}{l}\text { Metode } \\
\text { Toilet } \\
\text { training }\end{array}$} & Child oriented & $\begin{array}{c}19 \\
79,2 \%\end{array}$ & $\begin{array}{c}5 \\
20,8 \%\end{array}$ & $\begin{array}{c}24 \\
100 \%\end{array}$ & \multirow[t]{4}{*}{0,003} \\
\hline & Parent oriented & $\begin{array}{c}8 \\
320 \%\end{array}$ & $\begin{array}{c}17 \\
680 \%\end{array}$ & 25 & \\
\hline & Mix & $\frac{32,0 \%}{13}$ & $\frac{00,0 \%}{8}$ & 21 & \\
\hline \multicolumn{2}{|l|}{ Total } & $\begin{array}{c}40 \\
57,1 \%\end{array}$ & $\begin{array}{c}30 \\
42,9 \%\end{array}$ & $\begin{array}{c}70 \\
100 \%\end{array}$ & \\
\hline
\end{tabular}

Sumber : Data Penelitian Primer, 2017

Pada tabel 3 menunjukkan bahwa capaian keberhasilan toilet training terbesar adalah pada kelompok yang menggunakan metode parent oriented yaitu sebesar $68,0 \%$, kemudian metode campuran antara parent oriented dan child oriented (mix) sebesar $38,1 \%$ sedangkan persentase terkecil adalah metode child oriented yaitu sebesar 20,8\%.
Berdasarkan hasil analisis chi square test menunjukkan nilai signifikansi $p \quad(0,003) \quad<0,05$ sehingga dapat disimpulkan $\mathrm{H}_{1}$ diterima yang dapat diinterpretasikan bahwa dalam penelitian ini terdapat pengaruh yang bermakna dari metode toilet training terhadap variabel dependen.

\section{Uji Multivariat}

Tabel 4. Analisis Regresi Logistik Pengaruh Riwayat Pemakaian Popok dan Metode Toilet Training terhadap Keberhasilan Toilet training

\begin{tabular}{|c|c|c|c|c|c|}
\hline \multirow[t]{2}{*}{ Variabel } & \multirow[t]{2}{*}{ B } & \multirow[t]{2}{*}{ Sig } & \multirow[t]{2}{*}{$\operatorname{Exp}(B)^{*}$} & \multicolumn{2}{|c|}{ IK95\% ${ }^{(1)}$} \\
\hline & & & & Min & Maks \\
\hline Popok & 1.530 & 0.041 & 4.619 & 1.061 & 20.112 \\
\hline Metode TT ${ }^{(2)}$ & & 0.035 & & & \\
\hline Metode TT(1)(3) & 1.732 & 0.012 & 5.651 & 1.467 & 21.787 \\
\hline Metode TT(2)(4) & 0.628 & 0.370 & 1.874 & 0.475 & 7.390 \\
\hline
\end{tabular}

Keterangan :

${ }^{*} \operatorname{Exp}(\mathrm{B})$ : odds ratio

Sumber : Data Penelitian Primer, 2017

(1)IK : interval kepercayaan

TT : : toilet training

$\mathrm{TT}(1)$ : metode parent oriented dibandingkan dengan metode child oriented

TT(2) : metode mix dibandingkan dengan metode child oriented 
Dari analisis multivariat tersebut didapatkan hasil bahwa riwayat pemakaian popok dan metode toilet training secara bersama-sama mempengaruhi keberhasilan toilet training. Pada tabel 4 didapatkan nilai signifikan untuk variabel riwayat pemakaian popok 0,041 dan metode toilet training 0,035 karena keduanya memiliki nilai signifikan $<0,05$ maka variabel riwayat pemakaian popok dan metode toilet training signifikan mempengaruhi keberhasilan toilet training.

Kekuatan pengaruh dari kedua variabel bebas dapat dilihat dari nilai OR (odds ratio). Berdasarkan tabel 4 dapat diinterpretasikan bahwa anak balita yang memakai popok

\section{PEMBAHASAN}

Perubahan tren keberhasilan toilet training yang terjadi beberapa dekade terakhir dapat dipengaruhi oleh faktor murahnya harga diaper dan kurangnya ketersediaan waktu bagi orang tua atau pengasuh dalam melatih toileting anakanaknya [8].

Dalam penelitian ini, usia ratarata anak adalah 34,7 bulan sedangkan usia rata-rata keberhasilan toilet training pada penelitian ini adalah 36,6 bulan. Usia keberhasilan tersebut lebih panjang daripada pada penelitian Homman et al. ${ }^{[9]}$ yang menyatakan 25 bulan dan pergi ke toilet secara mandiri pada usia 31 bulan.

Usia anak saat dimulainya toilet training saat ini mengalami kemunduran, dimana sekitar 30 tahun yang lalu anak memulai toilet training sebelum mencapai usia 18 bulan sedangkan saat ini usia ratarata anak memulai toilet training adalah 21-36 bulan ${ }^{[10]}$. Hal tersebut kain memiliki kecenderungan untuk mencapai keberhasilan toilet training sebesar 4,619 kali daripada anak balita yang memakai popok sekali pakai. Hasil analisis pada metode toilet training sehingga dapat diinterpretasikan bahwa anak balita yang dilatih menggunakan metode parent oriented memiliki kecenderungan untuk mencapai keberhasilan toilet training 5,651 kali daripada anak balita yang dilatih menggunakan metode child oriented sedangkan metode mix tidak berbeda kecenderungannya dengan metode child oriented dalam mempengaruhi keberhasilan toilet training karena nilai $p>0,05(0,37)$.

sejalan dengan penelitian ini dimana usia rata-rata dimulainya pelatihan BAB dan BAK pada anak adalah usia 22 bulan.

Beberapa temuan dari penelitian Homman et al. [9] di Iran antara lain orang tua percaya bahwa usia yang tepat untuk lepas dari diaper adalah kurang dari 12 bulan (21\%), $12-24$ bulan $(70,2 \%)$ dan lebih dari 24 bulan (8,8\%). Hal tersebut tidak jauh berbeda dengan hasil penelitian ini yaitu mayoritas orang tua atau pengasuh memulai pelatihan $\mathrm{BAB}$ dan BAK secara mandiri pada usia 24-30 bulan (48,5\%;50\%).

\section{Pengaruh Riwayat Pemakaian Popok terhadap Keberhasilan Toilet Training}

Secara umum, popok dibedakan menjadi 2 jenis yaitu popok sekali pakai (disposable diaper) dan popok kain (cloth/reusable diaper). Popok sekali pakai memiliki produk absorbent yang dapat menyerap dan menahan 
cairan dalam rentang waktu tertentu sehingga anak dapat terhindar dari kontak langsung dengan kotorannya dan membuat anak aman, nyaman dan bebas iritasi [11].

Popok sekali pakai terdiri dari 3 lapisan yaitu lapisan pertama atau lapisan atas (top layer) yang terbuat dari material polymer yaitu polypropylene berfungsi untuk penampungan awal cairan yang akan dilanjutkan ke bagian lapisan inti dan untuk mencegah kulit bayi agar tidak basah. Lapisan kedua adalah lapisan inti (diaper core layer) yang mengandung bubur kertas yang terbuat dari material cellulose dan super absorbent polymer atau Sodium Polyacrylate (SAP) untuk menyerap dan menahan cairan. Lapisan bawah (bottom layer) yang terbuat dari polyethylene untuk mencegah terjadinya kebocoran cairan karena lapisan ini tahan air. Sejak tahun 2011, berat dari popok sekali pakai menjadi lebih ringan yaitu dari 64,2 gram menjadi 36,3 gram [11]. Meskipun terdapat berbagai jenis merk dagang popok sekali pakai, secara umum komposisinya adalah sama [12].

Jenis popok kedua yaitu popok kain adalah popok yang dapat digunakan kembali setelah dicuci. Bahan dasar dari popok kain dapat berupa kain katun, namun saat ini popok kain juga dibuat dengan kain microfilament seperti microfleece dan microfiber. Berat rata-rata popok kain adalah 139,3 gram [11].

Berdasarkan hasil penelitian ini, menunjukkan bahwa popok sekali pakai memiliki pengaruh negatif terhadap keberhasilan toilet training sedangkan popok kain memiliki pengaruh positif terhadap keberhasilan toilet training. Hal tersebut semakin dikuatkan dengan hasil analisis multivariat yang menunjukkan anak balita yang memiliki riwayat pemakaian popok kain memiliki kecenderungan untuk mencapai keberhasilan toilet training sebesar 4,6 kali daripada anak balita yang memakai popok sekali pakai.

Penelitian Nunen et al. [1] mendukung hasil tersebut yang menyatakan bahwa dua penyebab utama keterlambatan keberhasilan toilet training adalah kurangnya waktu orang tua untuk melatih buang air (39\%) dan pemakaian popok sekali pakai (disposable diaper) (36,4\%). Dalam penelitian Thaman et al. (2014) disebutkan bahwa bayi-bayi yang memakai popok kain (cloth diaper) lebih cepat lepas popok dibandingkan dengan bayi-bayi yang memakai popok sekali pakai (disposable diaper).

Berdasarkan penelitian yang dilakukan oleh Koc et al. [13] usia inisiasi toilet training yang lebih cepat pada anak-anak pengguna popok kain dipengaruhi oleh kecenderungan ibu yang menggunakan popok kain (cloth diaper) merasa terbebani karena harus mencuci popok kembali sehingga mereka cenderung memulai toilet training pada usia yang lebih muda. Hal tersebut juga didukung dengan penelitian oleh Thaman et al. ${ }^{[6]}$ yang menyatakan frekuensi penggantian popok lebih sering terjadi pada pemakaian popok kain (cloth diaper) daripada popok sekali pakai. Hal tersebut kemungkinan berhubungan dengan daya serap popok kain yang tidak sebagus popok sekali pakai. 
Popok sekali pakai (disposable diaper) memiliki 3 langkah penyerapan agar anak terbebas dari kebasahan yaitu menampung urine secepatnya (catching urine), kemudian menyerapnya dengan kekuatan gel superabsorbent (absorption urine), dan mengunci cairan secara efisien dengan mengubah urine yang terserap menjadi gel yang tidak dapat keluar kembali dari lapisan dalam (unable re-exit) sehingga menghindarkan kulit anak dari kebasahan bahkan saat popok tertekan oleh tubuh anak (locking away) [14].

Daya serap yang tinggi pada popok sekali pakai (disposable diaper) membuat anak tidak menyadari dan tetap nyaman setelah buang air pada popoknya karena popoknya tetap kering. Hal tersebut menyebabkan anak menjadi terbiasa dan terlambat mengenal cara mengontrol buang air secara sadar. Berbeda dengan popok kain yang memiliki keterbatasan daya serap dan tidak secara sempurna mengunci cairan dikarenakan tidak terdapat gel sehingga lebih mungkin anak untuk mengembangkan sensitifitasnya terhadap kebasahan yang akan membantu anak dalam proses toilet training.

\section{Pengaruh Metode Toilet Training terhadap Keberhasilan Toilet Training}

Beberapa metode toilet training telah disebutkan dalam jurnal-jurnal internasional, namun pengaruh dan keefektifannya dalam keberhasilan toilet training masih belum dijelaskan. Terdapat 2 metode yang dinyatakan paling populer dalam beberapa dekade terakhir ini yaitu parent oriented dan child oriented [15].

Pada penelitian ini, metode parent oriented merupakan metode yang paling banyak digunakan orang tua atau pengasuh yaitu sebesar 35,7\%. Hasil tersebut didukung oleh penelitian yang dilakukan di Iran oleh Homman et al. [9] yang menunjukkan bahwa sebesar $3,4 \%$ orang tua tidak memiliki metode toilet training tertentu, 52,1\% menggunakan metode parent-structure oriented dan $44,4 \%$ menggunakan metode child oriented.

Pada penelitian tentang metode Brazelton child oriented menunjukkan bahwa metode parent oriented memberikan manfaat untuk menghindari disfungsi eliminasi. Metode ini juga terbukti berhasil diterapkan di Belanda dengan usia anak 3-7 bulan. Namun demikian, keberhasilan metode ini bergantung pada cara orang tua menerapkan metode toilet training. Belum terdapat penelitian yang membandingkan keefektifan antara metode child oriented dan parent oriented ${ }^{[8]}$.

Akan tetapi, metode toilet training yang merupakan bentuk pelatihan toileting yang diberikan pengasuh terbukti mempengaruhi keberhasilan toilet training. Semakin baik pelatihan yang diberikan maka semakin tinggi tingkat keberhasilan toilet training $(\mathrm{p}=0.002 ; \mathrm{OR}=$ 1.288). Meskipun pada penelitian tersebut tidak membandingkan metode toilet training secara langsung ${ }^{[16]}$. 


\section{SIMPULAN}

Berdasarkan hasil penelitian dan analisis data serta kajian pustaka yang telah dilakukan dapat ditarik kesimpulan sebagai berikut:

1. Karakteristik pemakaian popok sekali pakai (disposable diaper) dan popok kain (cloth diaper) pada anak balita 18-48 bulan di Kota Malang tahun 2017 adalah $80 \%$ dan $20 \%$.

2. Karakteristik metode toilet training yang diterapkan orang tua atau pengasuh pada penelitian sebanyak $34,3 \%$ menggunakan metode child oriented, $35,7 \%$ menggunakan metode parent oriented dan $30 \%$ menggunakan kombinasi antara metode child oriented dan parent oriented (mix).

3. Lebih banyak anak balita yang belum berhasil dalam toilet training yaitu sebesar $57,1 \%$ daripada yang telah berhasil toilet training yaitu $42,9 \%$.

4. Terdapat pengaruh negatif riwayat pemakaian popok sekali pakai (disposable diaper) terhadap keberhasilan toilet training.

5. Terdapat pengaruh positif riwayat pemakaian popok kain (cloth diaper) terhadap keberhasilan toilet training

6. Terdapat pengaruh metode toilet training terhadap keberhasilan toilet training pada sampel yang diteliti.

\section{DAFTAR PUSTAKA}

1. Nunen K., Kaerts N., Wyndaele J.J., Vermandel A., and Hal G.V., Parents' Views on Toilet Training (TT): A
Quantitative Study to Identify The Beliefs and Attitudes Of Parents Concerning TT. Journal of Child and Health Care, 2015, 19 (2): 265-274.

2. Mota D.M. and Barros A.J.D, Toilet Training: Situation at 2 Years of Age in A Birth Cohort. Journal de Pediatria, 2008, 84(5):455-462.

3. Vermandel A, Kampen $M$, Gorp C and Wyndaele J.J., How to Toilet Train Healthy Children? A Review of the Literature. Neurology and Urodynamics Wiley InterScience, 2008, 27:162166.

4. Soetjiningsih, 2013. Tumbuh Kembang Anak Edisi 2, EGC, Jakarta.

5. Vermandel A, Weyler J, Wachter S.D. and Wyndaele J.J., Toilet Training of Healthy Young Toddlers: A Randomized Trial Between a Daytime Wetting Alarm and Timed Potty Training. Journal Development Behaviour Pediatric, 2008, 29:191-196.

6. Thaman L.A. and Eichenfield L.F., Diapering Habits:A Global Perspective. Pediatric Dermatology, 2014, 31:15-18.

7. Dahlan M.S., 2013. Besar Sampel dan Cara Pengambilan Sampel dalam Penelitian Kedokteran dan Kesehatan, Salemba Medika, Jakarta.

8. $\mathrm{Wu}$, Hsi-Yang. Can Evidence-Based Medicine Change Toilet-Training 
Practice? Arab Journal of Urology , 2013, 11:13-18.

9. Homman, N., Safaii, A., Valavi, E., and AminiAlavijeh, Z., Toilet Training in Iranian Children: A CrossSectional Study. Iran J Pediatric 2013, 23 (2): 154158.

10. Kaerts N., Hal G.V., Vermandel A., and Wyndaele J.J., Readiness Signs Used to Define the Proper Moment to Start Toilet Training: A Review of the Literature. Neurourology and Urodynamics Wiley Periodocals, 2012, 31:437440.

11. Frency S.F. Ng , Subramanian Senthilkannan Muthu , Yi Li and Patrick C.L. Hui., A Critical Review on Life Cycle Assessment Studies of Diapers. Institute of Textiles and Clothing, The Hong Kong Polytechnic University, Hung Hom, Kowloon, Hong Kong, China, 2013.

12. Kosemund K., Schlatter H., Ochsenhirt J.L., Krause E.L., Marsman D.S., and Erasala G.N., Safety evaluation of superabsorbent baby diapers. Regulatory Toxicology and Pharmacology Elsevier, 2008, 53:81-89.

13. Koc I., Camurdan A.D., Beyazova U., Ilhan M.N., and Shahin F., Toilet training in Turkey: The Factors That Affect Timing And Duration In Different Sociocultural
Groups. Child:Journal Compilation Blackwell, 2008.

14. Erasala, G.N., Romain, C, dan Merlay, I., Diaper Area and Disposable Diapers. Curr Probl Dermatol. Basel, Karger, 2011, 40:83-89.

15. Russel, Kelly., Among healthy children, what toilettraining strategy is most effective and prevents fewer adverse events (stool withholding and dysfunctional voiding)? Part A: Evidencebased answer and summary. Evidence for clinicians Paediatr Child Health, 2008, 13:3

16. Santoso, Ravinta L.C.P., Ratnawati, Linda dan Mastuti, $\mathrm{Ni}$ Luh Putu Herli. 2016. Faktor-Faktor yang Mempengaruhi Keberhasilan Toilet Training di TK Kecamatan Turen Kabupaten Malang. Tugas Akhir. Tidak diterbitkan, Fakultas Kedokteran Universitas Brawijaya, Malang. 